\title{
LAS ORGANIZACIONES DE MIGRANTES MEXICANOS EN USA Y SU ESTRATEGIA DE DESARROLLO LOCAL CON ENFOQUE TRASNACIONAL: AVANCES Y DESAFÍOS
}

\author{
MEXICAN MIGRANT ORGANIZATIONS IN THE USA AND THEIR \\ STRATEGY FOR LOCAL DEVELOPMENT WITH A TRANSNATIONAL \\ APPROACH: ADVANCES AND CHALLENGES
}

\author{
Rodolfo García Zamora \\ Juan Manuel Padilla \\ Universidad Autónoma de Zacatecas. México/Mexico \\ rgarciaz@prodigy.net.mx \\ padilla@,cantera.reduaz.mx
}

Recibido/Received: 22/11/2011

Modificado/Modified: 05/03/2012

Aceptado/Accepted: 26/03/2012

\section{RESUMEN}

El programa "Tres por Uno" de remesas colectivas en México, con sus variantes, conflictos y dificultades, ha sido un gran avance como esfuerzo organizativo transnacional de promoción del desarrollo social en las comunidades de origen. La clave de su éxito radica en la solidaridad de las organizaciones de migrantes hacia sus comunidades de origen en asociación con los tres niveles del gobierno mexicano. Esta filantropía transnacional se inicia desde los años sesenta del siglo anterior de manera espontánea y hasta treinta años después comienza a recibir apoyos paulatinos de los diferentes niveles del gobierno hasta su institucionalización como programa federal en el 2002 dependiendo de la Secretaría de Desarrollo Social. En el 2010, luego de más de tres décadas de experiencia de proyectos solidarios las organizaciones migrantes mexicanas se plantean avanzar hacia una nueva fase de desarrollo local con enfoque transnacional en sus regiones de origen buscando un mayor impacto en la estructura económica y social.

\section{PALABRAS CLAVE}

Clubes Migrantes, Migración, Proyectos Comunitarios, Proyectos de inversión, Trasnacionalismo.

\section{SUMARIO}

1. Introducción. 2. Surgimiento y avance de los proyectos comunitarios migrantes. 3. El impacto económico del programa 3x1 en México. 4. Impactos cívicos y sociales del programa 3x1 en México. Bibliografia.

\footnotetext{
ABSTRACT

The "Three for One" program of collective remittances in Mexico, with its variations, conflicts and difficulties, has been a major breakthrough as a trans-national, organizational effort for the promotion of social development in communities of origin. The key to its success lies in the solidarity of migrant organizations toward their home communities in association with the three levels of the Mexican Government. This transnational philanthropy began spontaneously in the 1960s and thirty years later it
} 
began to receive the gradual support of the different levels of the government, until its institutionalization as a federal program in 2002, reporting to the Ministry of Social Development. In 2010, after more than three decades of experience with solidarity projects, the migrant Mexican organizations are considering moving towards a new phase of local development -with a transnational approach- in their regions of origin, seeking greater impact on the economic and social structure.

\section{KEYWORDS}

Migrants, migration, community projects, project investment, trans-nationalism.

\section{CONTENTS}

1. Introduction. 2. The rise and progress of migrant community projects. 3 . The economic impact of the 3x1 program in Mexico. 4. Civic and social impacts of the 3x1 program in Mexico. References.

\section{INTRODUCCIÓN}

En los últimos quince años, aparejado al crecimiento de la migración internacional de México a los Estados Unidos que llega a los 12 millones de mexicanos radicados en aquel país, y de un crecimiento espectacular de las remesas familiares que ingresan a México, que en 2008 ascienden a 26 mil millones de dólares, se da un creciente protagonismo de más de 900 organizaciones de migrantes en Estados Unidos debido a su contribución al financiamiento de más de 12 mil proyectos sociales de infraestructura básica en las comunidades de origen. Este protagonismo es resultado de un proceso organizativo transnacional que tiene sus orígenes en los años sesenta del siglo anterior, en el caso de las organizaciones migrantes provenientes de la región histórica del Centro-Occidente como Zacatecas, Michoacán, Guanajuato y Jalisco (con más de cien años de experiencia migratoria internacional), que explica cómo desde ese periodo estuvieron promoviendo proyectos sociales en sus comunidades de origen empleando únicamente sus remesas colectivas. Etapa que ellos mismos han denominado como la de "Cero dólares por Uno", misma que funcionó sólo con sus aportaciones como instrumento de financiamiento de los proyectos comunitarios transnacionales y que sirvió como antecedente para que en los años ochenta se pudiera negociar con algunos municipios, de manera informal, para la realización de esos proyectos bajo la modalidad de "Uno por Uno", un dólar de los clubes migrantes por un dólar de los ayuntamientos, y que al inicio de los años noventa se transforma en Zacatecas y Guerrero en una modalidad formal de "Dos por Uno", un dólar de los migrantes por un dólar del gobierno federal y otro del gobierno estatal. En 1999, en Zacatecas se establece el Programa "Tres por Uno", al aportar los municipios un dólar adicional aprovechando el incremento de sus ingresos provenientes del presupuesto federal.

La importancia del $3 \times 1$ como valiosa experiencia de filantropía transnacional es reconocida por el gobierno mexicano a tal grado que en 2002 decide crear el programa " $3 x 1$ Iniciativa Ciudadana" a cargo del Programa de Microrregiones de la Secretaría de Desarrollo Social (Sedesol) con un presupuesto específico por primera vez, ya que anteriormente los gobernadores negociaban con esa dependencia el financiamiento de los proyectos sociales de los migrantes bajo la cobertura de otros programas ya establecidos como el Programa de Empleo Temporal que servían de protección para canalizar el apoyo financiero. No obstante lo reducido del presupuesto del Programa 3x1, que en su inicio, en 2002, cuenta con un presupuesto federal de 10 millones de dólares para 924 proyectos, en 247 municipios del país 
y que para 2009 asciende a 50 millones de dólares para 2.421 proyectos en 564 municipios, que contrasta con los más de 50 millones de dólares que los migrantes mexicanos estuvieron mandando diariamente al país en los últimos cinco años, el Programa ha sido un gran éxito institucional al establecer un nuevo espacio de negociación transnacional entre las organizaciones de migrantes, las comunidades y los tres niveles del gobierno mexicano; al propiciar mayor credibilidad hacia el gobierno responsable de administrar el Programa y fomentar el fortalecimiento de las relaciones entre las comunidades de origen de los migrantes y sus organizaciones en el exterior.

\section{EL SURGIMIENTO Y AVANCE DE LOS PROYECTOS COMUNITARIOS MIGRANTES}

La larga tradición de migración México-Estados Unidos con más de cien años en su región centro-occidental, la vecindad entre los dos países y la masividad de ese fenómeno con 30 millones de personas de origen mexicano en Estados Unidos, explican, entre otros factores, el surgimiento, avance y creciente protagonismo transnacional de las organizaciones migrantes mexicanas, especialmente en lo que respecta a su contribución a elevar el bienestar en sus comunidades de origen con el financiamiento de miles de proyecto sociales de infraestructura básica en asociación con los tres niveles de gobierno. De hecho, hoy se reconoce que esas organizaciones y sus proyectos con remesas colectivas han tenido los siguientes impactos positivos (García Zamora, 2005):

a) Promueven la organización comunitaria transnacional.

b) Posibilitan la interlocución de las comunidades de origen y de los migrantes con los tres niveles de gobierno.

c) Promueven la construcción de infraestructura social en regiones y comunidades tradicionalmente olvidadas.

d) Generan un proceso de aprendizaje social transnacional interinstitucional.

e) Apoyan al surgimiento de un nuevo actor social transnacional del desarrollo local.

f) Ayudan a promover una cultura de transparencia y rendimiento de cuentas que comienza a crecer en las comunidades y municipios donde se realizan proyectos.

Sin embargo, los proyectos sociales de los migrantes no han estado exentos de problemas y dificultades en su selección, diseño y realización. En este sentido, Manuel Orozco (2004), destaca tres aspectos importantes:

a) Frecuentemente, las donaciones de los migrantes son mayores que los recursos públicos para los proyectos sociales de las comunidades.

b) Existen múltiples contradicciones entre los clubes y los gobiernos municipales y estatales por la selección de las obras, la calidad de su construcción y mantenimiento.

c) La debilidad organizativa de las comunidades limita su capacidad de control sobre las inversiones, la calidad de los proyectos y el mantenimiento de las obras.

El mismo investigador, después de una rigurosa evaluación de la organización de los migrantes mexicanos y sus proyectos, destaca cinco lecciones importantes:

a) $\mathrm{Su}$ potencial para apoyar propuestas de desarrollo. La acción de los clubes de migrantes en esta área aumenta las oportunidades económicas en zonas de alta migración internacional. Sin embargo, la motivación de los clubes para participar en la promoción del 
desarrollo requiere entender sus prácticas, sus visiones y proyectos, para poder identificar oportunidades de colaboración con ellos.

b) Su compromiso con proyectos significativos de desarrollo. Ellos tienen la capacidad de promover y respaldar proyectos de desarrollo local a pequeña escala.

c) Su diversidad. Existe una gran diversidad de clubes y de organizaciones de migrantes mexicanos, con claras diferencias entre las Federaciones de Zacatecas, Michoacán, Jalisco, Puebla, Oaxaca, Yucatán, entre otros. Incluso, entre Federaciones del mismo estado como Zacatecas en el Sur de California, Illinois y Norte de Texas hay notables diferencias y al interior de cada una de ellas hay diversidad entre sus integrantes, en su antigüedad, su funcionamiento, su participación, su autonomía, sus experiencias con los proyectos y con las instituciones mexicanas en los tres niveles de gobierno.

d) Colaboración. Existe diferente habilidad para la colaboración y asociación con otras organizaciones sociales como resultado de la propia historia y experiencia de cada club y Federación de migrantes.

e) Identificación de las necesidades comunitarias. Los clubes y comunidades de origen pueden jugar un papel muy importante como agentes del desarrollo local para realizar una agenda de proyectos sociales y económicos prioritarios para el desarrollo local y regional. Pero ello requiere promover una mejor organización comunitaria transnacional integral en el ámbito institucional, social, educativo, económico, de liderazgos comunitarios transnacionales, etc. Este es uno de los retos estratégicos a que se enfrentan los clubes y migrantes mexicanos.

Los elementos anteriores son de gran importancia cuando Federaciones de clubes de migrantes mexicanos como las de Zacatecas, Michoacán, Oaxaca, Guerrero y otras buscan transitar de los proyectos sociales a los micro proyectos productivos y hacia las propuestas de desarrollo local con enfoque transnacional, bajo las cuales el programa 3x1 será una acción más dentro de un conjunto de actividades para ese fin. Para valorar la posibilidad de lograr dicha transición en los próximos años resulta muy importante valorar los impactos del Programa 3x1 a nivel económico, político, cívico-social y cultura.

\section{EL IMPACTO ECONÓMICO DEL PROGRAMA 3X1 EN MÉXICO}

Los cuadros siguientes muestran un crecimiento muy importante en el número de proyectos realizados, municipios involucrados y montos invertidos, de lo que se podría inferir que el impacto económico del programa ha sido muy importante. Sin embargo, si comparamos la inversión federal para este Programa en los últimos años resulta que representa aproximadamente el $0.03 \%$ de la inversión pública federal, en el caso de Zacatecas, el porcentaje es del $0.01 \%$ del presupuesto estatal en 2009. Los datos anteriores no deben llevarnos a la conclusión precipitada de que este Programa no tiene importantes impactos económicos, los tiene pero a nivel local. En estados como Michoacán y Zacatecas, los proyectos de infraestructura social como agua, drenaje, energía eléctrica, urbanización, pavimentación y centros comunitarios, son las principales obras de inversión en muchos de sus municipios con importantes efectos multiplicadores en la economía local a nivel de empleo, compra y venta de materiales, etc. De hecho, esta situación ha propiciado que con frecuencia los alcaldes se hayan convertido en promotores de la formación de nuevos clubes de migrantes para poder realizar un mayor número de inversiones comunitarias que incrementen la obra pública durante su gestión. Otro impacto económico en el ámbito local 
lo representan las obras de infraestructura física y los proyectos emergentes de salud, educación y becas, todos ellos obligación del Estado mexicano, pero, que promovidos por las organizaciones migrantes permiten elevar el nivel de vida de la población y posibilitan el fortalecimiento del tejido productivo y social local para avanzar hacia un nuevo tipo de actividades económicas y sociales que permitan superar la fragilidad estructural prevaleciente que ha propiciado en gran medida la creciente emigración internacional.

Tabla No. 1. Presentación del Programa 3x1 en la Organización de Estados Americanos por la Secretaría de Desarrollo Social de México.

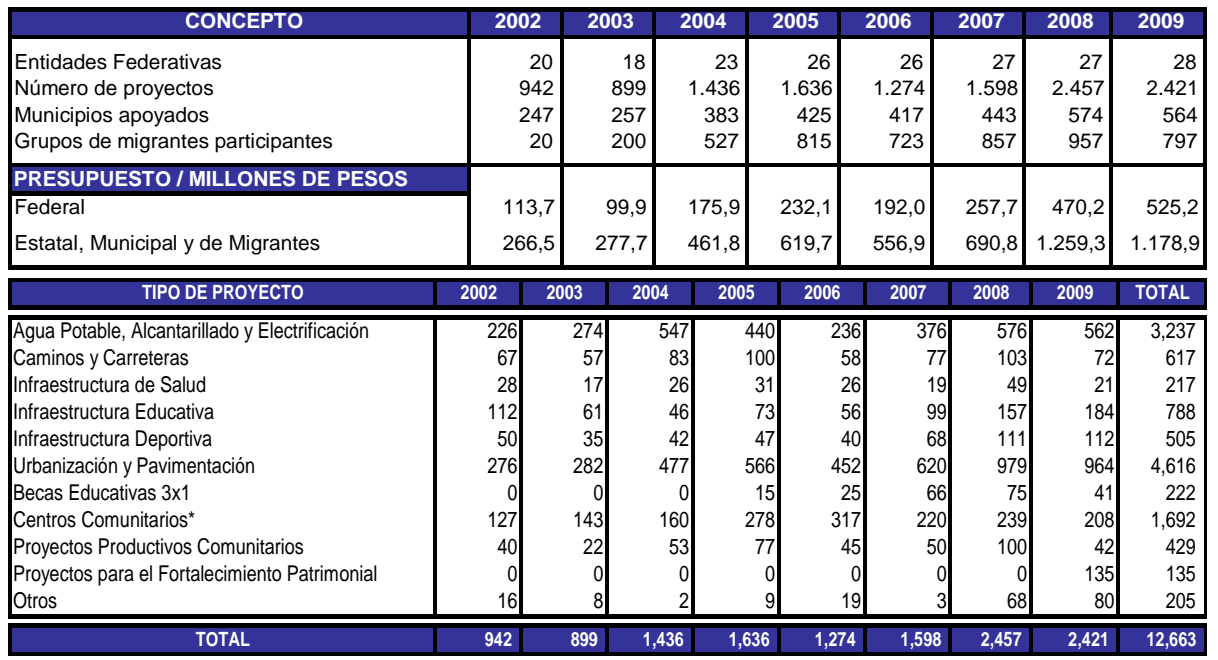

El tercer impacto económico significativo lo representa el interés que tienen algunas organizaciones de migrantes mexicanos, como las Federaciones de Clubes Zacatecanos y Michoacanos, por pasar de los proyectos sociales de infraestructura básica a los proyectos productivos después de varios años de haber promovido cientos de proyectos sociales en sus comunidades de origen. A este reto formidable se le ha denominado como "el paso de la muerte" (García Zamora, 2003) por su enorme complejidad, porque nos enfrenta a la debilidad institucional del propio país para promover la inversión productiva y a la ausencia de cultura empresarial en la comunidad migrante en general. Pese a tales dificultades, ambas Federaciones han estado luchando en los últimos cinco años porque la Secretaría de Desarrollo Social promueva de forma especial la vertiente de proyectos productivos de migrantes (429 proyectos del 2002 al 2009), los cuales han crecido de forma paulatina, especialmente, en esos estados con los invernaderos para la producción de tomate, explotaciones ganaderas y producción de agave y mezcal.

La contribución del programa "Tres por Uno" al bienestar de las comunidades de origen de los migrantes es indudable, pero transitar institucionalmente a la etapa de los proyectos productivos implica ubicarnos en una lógica cualitativamente distinta, empresarial, de rentabilidad, de mercado, de eficiencia, como criterios de consistencia de las propuestas y sustentabilidad económica de los proyectos. Los avances y aportes del programa "Tres por Uno" respecto a la organización comunitaria transnacional, los nuevos espacios de concertación, las redes sociales transnacionales, incluso, las diferentes propuestas del 
Consejo Consultivo del Instituto de los Mexicanos en el Exterior (formado por 130 representantes migrantes), pueden ser un apoyo importante para diseñar una estrategia específica de apoyo técnico, organizativo y financiero para los proyectos productivos de los migrantes mexicanos. Pero, pretender mezclar los proyectos solidarios con los productivos, con la normatividad y funcionamiento actual del Programa, tiene el riesgo enorme de destruir el Programa "Tres por Uno" como patrimonio de los migrantes, de la comunidad transnacional mexicana y del país mismo. Al romper la lógica solidaria, filantrópica, con la lógica del lucro, en contextos caracterizados en su mayoría por la ausencia de la cultura empresarial.

El riesgo anterior implica perder un esfuerzo de la comunidad transnacional mexicana que ha tardado cuarenta años de aprendizaje social, de construcción de nuevos espacios de concertación con los tres niveles de gobierno y creación incipiente de un nuevo tipo de políticas públicas hacia los migrantes, sus comunidades y sus proyectos. El problema radica en esclarecer si es viable transitar hacia la etapa de los proyectos productivos y el desarrollo local con enfoque transnacional bajo el programa "Tres por Uno" mediante una reforma a fondo del mismo o si este sigue promoviendo los proyectos de la filantropía transnacional y se crea un nuevo programa federal de apoyo a los proyectos productivos y el desarrollo local transnacional. Bajo la perspectiva anterior, resulta interesante como la misma Secretaría de Desarrollo Social, el 29 de enero 2009, frente a los impactos económicos y sociales de la crisis financiera norteamericana sobre México, da a conocer en el Diario Oficia de la Federación el Programa Proyectos Productivos para el Fortalecimiento Patrimonial: Un Fondo para financiar proyectos individuales o familiares en México, dentro del marco del Programa 3x1 para Migrantes.

El Fondo Migrante para Proyectos Productivos para el Fortalecimiento Patrimonial se crea, según la exposición de motivos del Diario Oficial, por la constante demanda por parte de los migrantes de generar oportunidades en sus comunidades de origen que les permitan incrementar su patrimonio y el de sus familias, así como brindar fuentes de empleo a los jóvenes con el fin de reducir sus necesidades de emigrar. Cabe recordar que dicha demanda fue planteada en varias ocasiones por los Consejeros del Consejo Consultivo del Instituto de los Mexicanos en el Exterior en sus recomendaciones al Gobierno Mexicano. Bajo este nuevo mecanismo de inversión, la Sedesol aportará el 50\% de inversión por proyecto y los migrantes aportarán el otro $50 \%$. Con estos recursos se apoyarán proyectos productivos individuales o familiares presentados por migrantes radicados en el exterior, que se realicen en territorio mexicano, con un monto federal máximo, por proyecto, de hasta $\$ 300$ mil pesos (30 mil dólares). Para poder recibir recursos orientados a Proyectos Productivos para el Fortalecimiento Patrimonial, los migrantes mexicanos radicados en el extranjero deberán cumplir con los siguientes criterios:

a) Tener nacionalidad mexicana.

b) Pertenecer a un club de migrantes registrado dentro del Programa $3 \times 1$.

c) Presentar solicitud de Proyecto Productivo Patrimonial.

d) Presentar Perfil de Plan de Negocios (se considera hasta un 15\% del monto total del proyecto para asesoría técnica, elaboración del Plan de Negocios, instrumentación y seguimiento).

e) Mostrar solvencia económica para poder cubrir las aportaciones que corresponden al migrante para la ejecución del proyecto.

A finales del mes de enero de 2010, el Instituto de los Mexicanos en el Exterior da a conocer un nuevo programa de inversión productiva para migrantes denominado "Paisano 
Invierte en Tu Tierra" promovido por la Secretaría de Agricultura y Fideicomiso de Riesgo Compartido (FIRCO). Este Programa busca fortalecer el potencial económico de los migrantes y el uso productivo de las remesas.

Los elementos que pretenden justificar el nuevo Programa son:

a) El crecimiento económico y el desarrollo del campo mexicano requieren de recursos para ser invertidos en proyectos que produzcan empleos y riqueza.

b) Existe gran potencialidad de las más de 21 mil millones de dólares de remesas que recibió México en 2009 y un mercado "nostálgico" que consume más de 24 mil millones de dólares al año en Estados Unidos.

c) Necesidad de apoyo y estímulo gubernamental para el uso productivo de las remesas.

El objetivo central de este programa consiste en contribuir a que las remesas se conviertan en recursos productivos mediante la inversión en negocios de los migrantes y sus familias.

Los principales objetivos específicos son los siguientes:

a) Fomentar el empleo en las comunidades de origen para reducir el despoblamiento y la emigración.

b) Aprovechar el mercado nostálgico en Estados Unidos.

c) Superar la relación de dependencia de las remesas en una relación de socios productivos.

d) Fortalecer las relaciones intergeneracionales de los migrantes con México.

Población objetivo y condiciones. Productores en México o el extranjero que apoyados en las remesas, decidan invertir en proyectos productivos en el país. Productores nacionales que se orienten hacia el mercado nostálgico.

Tipo de proyectos:

a) Agroindustria.

b) Turismo rural.

c) Agricultura protegida (invernaderos).

d) Producción orgánica.

e) Sistemas de energía renovable.

f) Fábricas para el procesamiento de ganado.

Requisitos:

a) Contar con remesas u orientación hacia el mercado de la nostalgia.

b) Presentar un proyecto de inversión rentable.

c) Presentar solicitud en Gerencia estatal de Firco o en el Consulado que corresponda.

Este nuevo programa intenta responder a una larga demanda de las organizaciones de migrantes mexicanos en el exterior interesadas en contar con un Programa de apoyo específico para inversiones productivas en sus comunidades de origen por parte del gobierno federal. Siendo su puesta en marcha un avance, es importante valorar sus debilidades y riesgos, dentro de las cuales se encuentran las siguientes:

a) Baja organización y capacitación de las comunidades de origen y las organizaciones de migrantes.

b) Ausencia de cultura empresarial.

c) Ausencia de programas de formación y capacitación micro empresarial y de apoyo técnico permanente.

Pero el anuncio de este Programa también representa retos y oportunidades para la colaboración entre diversos actores sociales interesados en los proyectos productivos de los 
migrantes, sus comunidades de origen y el desarrollo local con enfoque transnacional. A continuación enumeramos algunos de los más importantes:

a) Colaboración interinstitucional entre dependencias federales, estatales, municipales, comunidades de origen y clubes.

b) Oportunidad de construir programas de organización y capacitación comunitaria transnacional entre las comunidades de origen los clubes, las instituciones educativas, organizaciones no gubernamentales, etc.

c) Oportunidad de construir Programas de Micro y Pequeñas Empresas Transnacionales entre comunidades de origen, clubes, organizaciones empresariales, organismos gubernamentales, instituciones internacionales e instituciones educativas.

d) Oportunidad de colaboración permanente entre las comunidades de origen, los clubes, las universidades, organizaciones no gubernamentales, en programas de investigación, extensión y formación continua.

e) Posibilidad de articular el Programa $3 \times 1$ en su vertiente social y micro productiva, con las acciones anteriores en una estrategia de desarrollo regional con enfoque transnacional. En Zacatecas, la Universidad Autónoma viene trabajando en varios proyectos de desarrollo local con enfoque transnacional, junto con las comunidades de origen, las organizaciones migrantes y los ayuntamientos de Valparaíso, Jerez y Juchipila. Buscando expandir estas actividades con una mayor colaboración con la Federación de Clubes Zacatecanos del Sur de California y su oficina en Zacatecas, dedicada a apoyar la mejor realización de los proyectos $3 \times 1$, pero con un enfoque de desarrollo local transnacional. Para lo cual se han iniciado en abril de 2010 algunos talleres en Los Ángeles, California, con la Asociación de Clubes Nochistlenses, muy interesados en mejorar los proyectos filantrópicos y micro productivos y avanzar hacia una estrategia de desarrollo regional con enfoque transnacional para el Sur de Zacatecas.

\section{LOS IMPACTOS CÍVICOS Y SOCIALES DEL PROGRAMA 3x1 EN MÉXICO}

La larga historia filantrópica de las organizaciones migrantes mexicanas de más de 50 años, desde abajo y desde adentro de la comunidad migrante a favor de sus comunidades de origen en sus diferentes etapas del Cero por Uno, Uno por Uno, Tres por Uno, etc. no sólo ha aportado un aumento en el bienestar de la población local con los más de 12 mil proyectos de infraestructura básica, sino también y de manera especial, importantes impactos cívicos y sociales tanto en las comunidades de origen como de destino. La salida creciente de mexicanos hacia los Estados Unidos, que al inicio de los años setenta representaba un stock de 800 mil migrantes en aquel país y se incrementa radicalmente en 2010 a 12 millones de mexicanos (la mitad indocumentados) se da en el contexto de un deterioro del tejido económico, social y político del país. El modelo económico sustitutivo de importaciones desde los años sesenta muestra indudables síntomas de agotamiento; se incrementa la profunda crisis agrícola y rural, y el cuestionamiento hacia el sistema político nacional dominado por un sólo partido durante más de 70 años. Así, la salida constante y creciente de mexicanos hacia el país del Norte, representaba entre otros efectos, un sentimiento de expulsión económica y social del país por la incapacidad gubernamental y de su partido oficial de una adecuada gestión de la economía y del país en su conjunto. Las primeras acciones filantrópicas de obras sociales realizadas por las organizaciones migrantes mexicanas en Estados Unidos a favor de sus comunidades de origen en los años sesenta del 
siglo anterior partían de asumir que el Estado mexicano no cumplía con sus obligaciones de proporcionar la suficiente inversión pública para atender las diversas necesidades de esas comunidades. De esta manera, implícitamente la realización de esos proyectos comunitarios significaba un cuestionamiento político y una respuesta organizativa desde abajo y desde el exterior para colaborar en la satisfacción de esas necesidades. Estas iniciativas significan el inicio de un largo proceso de aprendizaje transnacional a nivel cívico, social y político entre comunidades de origen y organizaciones migrantes. Durante más de treinta años las comunidades solicitan la colaboración de sus migrantes para atender diversas necesidades y esa práctica solidaria transnacional posibilita que en los años ochenta algunos alcaldes colaboren en iniciativas informales de financiamiento "Uno por Uno", que representa el antecedente para que surjan el Zacatecas y Guerrero, al inicio de los noventa, los Programas "Dos por Uno", que posteriormente deviene en "Programa Tres por Uno" en Zacatecas y "Programa Tres por Uno Iniciativa Ciudadana", en 2002 como programa nacional tal como indicamos antes.

La institucionalización del programa "Dos por Uno" en Zacatecas en 1992, y, posteriormente, del programa "Tres por Uno" en 1999, significa el reconocimiento gubernamental de una larga filantropía transnacional con un nuevo actor social que son las organizaciones de migrantes mexicanos en Estados Unidos, cuyos dirigentes adquieren con frecuencia un amplio reconocimiento político y social en las comunidades de origen y destino por su compromiso solidario con ambas. Así, la creación del programa "Tres por Uno Iniciativa Ciudadana" por parte de la Secretaría de Desarrollo Social busca institucionalizar esa filantropía espontánea, desde abajo y desde el exterior dentro una incipiente política social transnacional en México (Fernández de Castro, García Zamora y Vila, 2006). Esto significa la construcción de un nuevo espacio transnacional de interlocución y negociación entre los cuatro actores del Programa: los migrantes, los municipios, gobiernos estatales y el gobierno federal. Espacio en el cual permanentemente se presentan conflictos por las "reglas de operación" del Programa, dependiente del Programa de Microrregiones para zonas de alta marginación social de Sedesol. De hecho, esta ubicación institucional representa un problema de origen porque la mayoría de los migrantes internacionales mexicanos no provienen de zonas de alta marginación social, sino de zonas intermedias que deberían estar fuera de las acciones de Microrregiones. Después de ocho años de funcionamiento del Programa en su modalidad nacional no se ha modificado esta disfuncionalidad institucional.

En los primeros años del Programa "Tres por Uno Iniciativa Ciudadana", 2002, 2003, 2004 se dieron dos fuertes conflictos con las organizaciones migrantes y la Secretaría de Desarrollo Social que junto con la Secretaría de Hacienda deciden sus reglas de operación. El primero, consistió en el intento de privilegiar sólo las inversiones productivas y prohibir las inversiones sociales no productivas como reparación y construcción de templos, centros sociales, lienzos charros, etc. El segundo, se refería a marginar a las organizaciones de migrantes del proceso de solicitud, selección y realización de los proyectos, dejando tales funciones únicamente en los tres niveles de gobierno. Las Federaciones de Clubes Mexicanos, en particular, la de los Clubes Zacatecanos del Sur de California, con amplia trayectoria organizativa transnacional desde los años sesenta y en la realización de proyectos uno por uno, dos por uno y tres por uno realizan un fuerte proceso de presión y negociación con Sedesol, que indirectamente llega hasta el presidente Fox, quién había caracterizado a los migrantes como los "nuevos héroes mexicanos", del quien, finalmente, logran recuperar el derecho de financiar las obras sociales y comunitarias que las comunidades de origen y 
clubes consideren adecuadas, buscando al mismo tiempo avanzar hacia los proyectos productivos.

Sobre el segundo punto, que manifestaba una cierta competencia política entre los alcaldes y los Clubes, pero, también a nivel federal, que veían con preocupación el protagonismo social y político de las organizaciones de migrantes y sus dirigentes en la realización de este Programa y en otras esferas públicas y políticas, el gobierno mexicano tuvo que ceder. Tuvo que reconocer que ese programa como política pública surge como resultado de la iniciativa, de la práctica solidaria transnacional realizada por más de cuatro décadas y que las organizaciones migrantes, sus Federaciones de Clubes, deberán seguir participando en la selección y realización de los proyectos. La negociación de este punto fue tal que implicó modificar el nombre del programa a "Tres por uno para Migrantes" como se llama hasta la fecha. En los años posteriores han seguido suscitándose fricciones por los mecanismos de selección de los proyectos, por la forma de realización, por los mecanismos de seguimiento, entrega y mantenimiento de las obras de infraestructura realizadas. Un reclamo permanente de los migrantes hasta ahora, ha sido la falta de transparencia en la realización de los proyectos por parte de los municipios y gobiernos estatales; la mala calidad en muchas de las obras realizadas, el reducido control social y rendimiento de cuentas y falta de sanciones a empresas constructoras y funcionarios que han incurrido en ilícitos.

Estas demandas constantes de las organizaciones de migrantes y sus comunidades de origen propiciaron un avance institucional con la creación de los Comités de Validación y Atención Migrantes (COVAM) en cada estado de la república mexicana donde funciona el programa, presidido por el delegado federal de Sedesol, con las siguientes funciones (Diario Oficial: 28 de diciembre 2009):

a) La priorización, asignación, validación y dictaminarían de los proyectos a atender.

b) Determinar los criterios para la selección de proyectos, tanto aquellos que se ajusten al monto máximo señalado en estas reglas, como aquellos que superen dicho monto y someterlo a consideración de la Unidad Administrativa Responsable del Programa (UARP).

c) La calendarización para la entrega de aportaciones de cada uno de los participantes.

d) La participación de los migrantes o de sus representantes en las actas de entregarecepción de las obras.

e) La operación hacia el interior del COVAM, y, en su caso, los aspectos de planeación que considere pertinentes.

Además, el COVAM dictaminará también sobre el apoyo de proyectos que justifiquen que la aportación de los clubes u organizaciones de migrantes sea en especie, siempre que ésta se asocie directamente a la naturaleza y objetivos del proyecto y cuyo costo pueda ser cuantificable y demostrable. Los criterios generales que utilizará el COVAM para seleccionar los proyectos considerarán que la obra u acción contribuyan al máximo beneficio comunitario y en los proyectos de infraestructura se procurará que prevalezcan aquellos que incidan de manera directa en la calidad de vida de las comunidades. Para garantizar que la operación y ejecución del Programa se realice con toda transparencia, en el seno del COVAM se promoverá la apertura de cuentas mancomunadas entre los municipios, cuando éstos sean ejecutores, y los representantes de los migrantes. Asimismo, el COVAM dictaminará sobre aquellos proyectos que por su magnitud, impacto social y características específicas, requieran de un monto federal superior al establecido en estas reglas de operación o de una mezcla financiera diferenciada. Para la valoración de los proyectos productivos para el fortalecimiento patrimonial se realizará a través de su Subcomité formado 
específicamente para este propósito, en el seno del COVAM. Dicho Subcomité se denominará "Subcomité Técnico Valuador de Proyectos Productivos" y será responsable de:

a) Valorar técnicamente las propuestas.

b) Emitir las recomendaciones pertinentes al COVAM, indicando si considera pertinente o no la aprobación del proyecto y los motivos que fundamentan su opinión;

c) Proponer el esquema de acompañamiento técnico y empresarial para cada proyecto.

El Subcomité estará integrado por al menos 3 expertos en materia económica-productiva, cuya participación será honoraria. Los miembros del subcomité serán representantes de:

a) La Delegación Federal de Sedesol.

b) La Delegación Federal de la Secretaría de Economía.

c) Instituciones Académicas de Educación Superior u organismos de investigación especializados

La construcción del COVAM significa un avance institucional en la realización del programa "Tres por Uno para Migrantes", pero no termina con la asimetría que existe entre los cuatro actores del mismo en términos de información y capacidad. En efecto, los clubes y comunidades de origen pocas veces tienen toda la información de cada uno de los expedientes técnicos de cada proyecto y presentan una gran debilidad técnica frente a los profesionales de la administración pública de los municipios, gobiernos estatales, delegaciones federales y las empresas privadas que realizan las diferentes obras. La asimetría crece por la enorme debilidad organizativa y de capacitación en las comunidades de origen y destino y la imposibilidad de que los migrantes puedan estar viajando permanentemente a México para supervisar la realización de los proyectos. Esta situación provoca constante inconformidad por parte de los clubes respecto a que las reglas de operación del Programa son definidas sin su participación; que esas mismas reglas son violentadas con frecuencia cuando los alcaldes promueven la creación de clubes "fantasmas", sin membresía, sin vida comunitaria real en Estados Unidos y cuando les piden a los clubes que funcionan realmente avales "formales", sin aportación financiera para aumentar su obra pública e impacto político.

El reducido control social, la falta de transparencia, de rendimiento de cuentas y de sanciones a funcionarios y constructores que incurran en ilícitos son algunos de los problemas fuertes que confrontan a las organizaciones de migrantes con los tres niveles de gobierno mexicanos actualmente y las tensiones que ha provocado que Sedesol haya abierto delegaciones en Los Ángeles, California e Illinois con una nueva actitud de reducir la participación de las Federaciones de Migrantes en el acopio de iniciativas de proyectos, respaldo, seguimiento y evaluación de los mismos. Funcionarios federales pretenden justificar esa estrategia por un supuesto peligro de corporativización del Programa por parte de los Clubes migrantes (Palafox, 2010). Por su parte, Efraín Jiménez, destacado dirigente migrante de la Federación de Clubes Zacatecanos del Sur de California, considera que la estrategia del gobierno federal evidencia el corporativismo oficial hacia el Programa y el intento de control hacia los migrantes que han logrado grandes avances políticos en estados como Zacatecas y Michoacán, donde se ha modificado las Constituciones estatales para permitir que los migrantes puedan ser alcaldes y diputados locales. Él considera que esa estrategia atenta contra el futuro de las Federaciones de Clubes y que el gobierno mexicano actual deberá modificarla o crecerán las tensiones entre ambos (IFAI, 15 abril 2010).

El reclamo por un control social y rendimiento de cuentas no es nuevo como lo evidencian los resultados de la investigación realizada por Katrina Burges en Michoacán y Zacatecas sobre el "Tres por Uno" y el rendimiento de cuentas en 2005 (Ciudad de México, 
16 y 17 de abril, 2010). En los cuales diversas comunidades con proyectos de migrantes reconocen la importancia del control social y rendimiento de cuentas, aunque con frecuencia se ha avanzado muy poco en esos temas por la debilidad organizativa de las comunidades de origen y los clubes.

En el evento internacional "Retos y oportunidades en la cogestión de proyectos comunitarios transnacionales" realizado por la Universidad Tufts de Boston en la Ciudad de México los días 15 y 16 de abril de 2010, con más de 25 líderes migrantes mexicanos radicados en los Estados Unidos, ONGs, académicos y funcionarios de Sedesol, para analizar de manera especial que tanto se ha avanzado en los temas de control social y rendimiento de cuentas, las conclusiones son que ha habido avances, pero, insuficientes, ya que frecuentemente las comunidades de origen y los Clubes tienen poca información de los expedientes técnicos, de los mecanismos de asignación de los proyectos por parte de ayuntamientos y autoridades estatales y siguen existiendo poca claridad en la inversión de esos proyectos y mala calidad e incumplimiento en muchos de los mismos.

En la sesión de los Vínculos Transnacionales, se hicieron las siguientes propuestas:

1. Previo a los proyectos, es necesario realizar diagnósticos comunitarios transnacionales.

2. Elaboración conjunta de planes de desarrollo municipal donde se ubique el Programa 3x1 en una visión estratégica de desarrollo local.

3. Realizar programas de organización y capacitación comunitaria transnacional que posibilite la mejor realización de los proyectos e ir promoviendo la formación de una nueva generación de líderes en origen y destino.

4. Aprovechar las tecnologías de la información para la comunicación permanente entre las comunidades de origen clubes para la formación y capacitación. Se sugiere promover la creación de telecentros comunitarios como soporte técnico de esas y otras actividades transnacionales.

5. Promover y fortalecer la participación de las mujeres en todos los niveles. Promover políticas públicas y programas de Desarrollo y Migración con enfoque de género y equidad.

6. Buscar alianzas con las instituciones de educación superior para la mejor realización de los diferentes proyectos, para diseñar y desarrollar los programas de capacitación y para formular políticas de incidencia binacional. Aprovechar que la nueva Ley de Ciencia y Tecnología plantea que todas las universidades públicas deben promover unidades de vinculación social y extensión universitaria con las comunidades rurales y las colonias populares. (Respecto al 3x1 de proyectos productivos para fortalecimiento patrimonial las reglas de operación, como indicamos antes, ya incluyen la participación de las instituciones de educación superior como parte del Subcomité Técnico Valuador de los Proyectos Productivos, lo que abre la posibilidad de una mayor participación apoyo a los proyectos de los migrantes).

7. Integrar grupos de expertos universitarios en las diferentes disciplinas técnicas y científicas como grupo de acompañamiento para el mejor diseño de los proyectos, para la correcta selección de los mismos, para mejorar los mecanismos de seguimiento, evaluación y reingeniería. Propuesta que se sugiere se integre a las reglas de operación del COVAM.

8. Que las reglas de operación sean consensuadas con los clubes y comunidades de origen y no se definan sólo desde las Secretarías de Desarrollo Social y Hacienda sin tiempo ni posibilidad de modificar por aquellos.

9. Que las reuniones del COVAM se programen con toda anticipación y se entregue toda la información sobre los expedientes técnicos de los proyectos a evaluar. 
10. Fortalecer la organización y capacitación de las comunidades de origen para que puedan convertirse en responsable de su propio desarrollo, compartir el esfuerzo con los clubes migrantes, evitar un nuevo paternalismo y permitir el empoderamiento migrante en las comunidades de destino al reducir sus responsabilidades con el desarrollo local en México.

11. Lo anterior significa una visión estratégica de corresponsabilidad con el desarrollo local, mediante la cual en la medida que la comunidad de origen se apropia de su propio diagnóstico, formula su agenda de desarrollo local y los proyectos de aterrizaje de ésta, los migrantes como aliados estratégicos del desarrollo local, al reducir sus cargas en México, podrán fortalecer su incidencia, cabildeo, y empoderamiento político $\mathrm{y}$ económico en Estados Unidos, potenciado su carácter como aliado transnacional en beneficio de México y sus comunidades de origen.

12. Valorar la posibilidad de que los Comités de Obra de los proyectos $3 \times 1$ se conviertan en comités promotores del desarrollo local, mediante un proceso permanente de organización y capacitación con enfoque regional y transnacional.

13. Integrar las propuestas de las comunidades de origen y los clubes migrantes a los mecanismos institucionales de control social y rendimiento de cuentas que hasta ahora ha sido sólo a nivel gubernamental y han sido incapaces de garantizar la participación social, transparencia, calidad y la inversión correcta de los recursos públicos.

14. Si la propuesta anterior se integra en las nuevas modificaciones institucionales para la gobernanza del país y sus regiones, aunado a nuevos programas de organización y capacitación comunitaria transnacional, permitirá una relación menos asimétrica entre los cuatro actores del programa "tres por Uno", porque hasta ahora las comunidades de origen y los clubes están en desventaja en términos de información y capacitación respecto a los tres niveles de gobierno, caracterizados por el monopolio de la información y su profesionalización administrativa.

15. Se propone que los clubes destinen el $25 \%$ de los recursos recaudados a sus propios programas de organización y capacitación, fortalecimiento institucional y formación de nuevos liderazgos transnacionales como una respuesta estratégica a los retos de desarrollar mejor los proyectos sociales y productivos, empoderamiento en las comunidades de origen y destino, incidiendo en las políticas públicas de ambos países y al desafío del relevo generacional de clubes y federaciones de migrantes en la cual los hijos de mexicanos nacidos en Estados Unidos ocuparan un papel más trascendental tanto en su agenda de empoderamiento en aquel país como en sus alianzas con los actores en México comprometidos con el desarrollo local con enfoque transnacional. Este esfuerzo de fortalecimiento institucional podrá verse reforzado con el apoyo de fundaciones y organismos internacionales, organizaciones no gubernamentales y las instituciones educativas de ambos países.

El mismo tema de control social y rendimiento de cuentas adquiere un lugar central en el Taller de Organización Comunitaria Transnacional realizado por la Asociación de Clubes Nochistlenses en el Sur de California, el 22 de abril referente a una evaluación de las lecciones que ha dejado el programa "tres por Uno" para las comunidades de origen y clubes migrantes y los retos para el desarrollo local con enfoque transnacional (FCZSC, 22 abril 2010, UCLA, Long Beach University, UAZ). En efecto, en dicho evento realizado con 36 dirigentes migrantes del municipio de Nochistlán en el Sur de California respecto a la clave del éxito de los proyectos $3 \times 1$ en sus comunidades se enumeraron los siguientes factores:

a) Transparencia en el uso de los recursos y la voluntad de las comunidades y los clubes por realizar esos proyectos. 
b) El rendimiento de cuentas y la confianza entre los cuatro actores del 3x1.

c) Unidad de la comunidad y los clubes.

d) Las ganas de colaborar y ayudar de los clubes a sus comunidades.

e) El interés de los clubes por cambiar la fisonomía de los municipios de origen.

Respecto a las causas de fracaso de los proyectos $3 \mathrm{x} 1$, se mencionaron las siguientes:

a) Ausencia de transparencia en el uso de los recursos.

b) Falta de control social y rendimiento de cuentas.

c) Debilidad técnica de las comunidades y comités de obra.

d) Falta de claridad en la asignación de obras a las empresas constructoras y ausencia de sanciones a empresas incumplidas.

e) Debilidad técnica de los municipios.

f) Reglas de operación del Programa decididas en la Ciudad de México sin consultar a las comunidades de origen y los clubes.

Señaladas las causas del éxito y fracaso de los proyectos se hicieron las siguientes propuestas para mejorar el Programa y avanzar hacia una estrategia de desarrollo local con enfoque transnacional:

1. Promover mayor organización de las comunidades y los clubes.

2. Fortalecer y capacitar a los comités de obra.

3. Promover la cultura del control social en las comunidades y responsabilidad pública de los funcionarios.

4. Transparencia técnica y financiera de los expedientes técnicos de los proyectos, evitando la manipulación de los costos originales. Con libre acceso a ellos por parte de las comunidades y clubes.

5. Realizar alianzas con las instituciones educativas para capacitar a los comités de obras y asegurar una correcta supervisión técnica de los proyectos.

6. Fortalecer la capacidad técnica y administrativa de los municipios.

7. Establecer el servicio civil de carrera en los municipios para garantizar la permanencia de los funcionarios más capaces y honestos.

8. Establecer las cuentas bancarias mancomunadas entre los Comités de Obra y los Municipios para garantizar mayor transparencia, control social y la calidad en las obras realizadas.

9. Fortalecer la participación de mujeres en los clubes y comités de obra.

10. Promover una mayor capacitación técnica de los jóvenes en las comunidades. Que se les enseñe inglés y computación entre otras habilidades.

11. Definir metas de comunidades y clubes a 5, 10 y 20 años.

12. Hacer planes comunitarios y municipales a 10 y 20 , en los cuales insertar las acciones futuras del $3 \times 1$.

13. Promover la planeación estratégica entre comunidades de origen y clubes.

14. Fortalecer a las comunidades de origen para que realicen sus diagnósticos, su agenda de desarrollo, su planeación estratégica y de acción conjunta con los clubes, asignando un papel central a los jóvenes.

Ante la gran cantidad de propuestas se decidió resumirlas en tres acciones realizables a corto y mediano plazo:

1. Estrategia de fortalecimiento de corto plazo de comunidades clubes para la mejor realización de los proyectos sociales y productivos.

2. Promover mayor información, formación y capacitación en clubes y comunidades de origen. Diseñar y establecer un programa de formación de liderazgos comunitarios 
transnacionales con la colaboración de la Universidad de California Los Ángeles, la Universidad de Long Beach y la Universidad Autónoma de Zacatecas

3. Realizar un plan estratégico transnacional a 10 y 20 años con la realización de Talleres en Los Ángeles y en Zacatecas.

Ante la necesidad de darle continuidad a los trabajos realizados y previo a la etapa de planeación estratégica, la Asociación de Clubes Nochistlenses en el Sur de California, realizaron un segundo Taller de Diagnóstico el 5 de junio del 2010, señalando como los principales problemas y debilidades de esos clubes los siguientes:

1. La falta de preparación y acceso limitado a la High School y a la Universidad de los jóvenes de origen zacatecano.

2. La falta de perspectiva de empoderamiento en los Estados Unidos, para lo cual hay que promover toda una red de contactos sociales que potencien esa perspectiva.

3. Apatía y falta de apoyo de la propia comunidad nochistlense en EU.

4. Falta de unidad de los nochistlenses en EU.

5. Necesidad de mayor organización y personal capacitado. Aprovechar a los universitarios en EU de origen zacatecano, la colaboración y alianzas con las instituciones educativas en EU y México.

6. Enfoque excesivamente centrado en la organización de eventos y la recaudación de fondos para su realización. Mucho desgasta para organizar los aniversarios del 40 al $10^{\circ} \mathrm{y}$ poca dedicación a la organización y capacitación para el desarrollo comunitario.

7. Problema de becas para jóvenes zacatecanos en EU. Pese al apoyo del gobierno de ese país, la crisis hace difícil que los padres respalden a sus hijos para su ingreso al College y la Universidad.

8. Hace falta involucrar más a los jóvenes. Pensar en los retos de la $2^{\mathrm{a}}$ y $3^{\mathrm{a}}$ generación.

9. Buscar mecanismos para involucrar a los hijos de los inmigrantes en los clubes para afrontar el relevo generacional.

10. Alta dependencia de los Clubes respecto al Programa 3x1. Surgen con ese Programa y por él, y ahora hay prácticas gubernamentales de Sedesol que atentan contra ellos. Necesidad de reinventar a los clubes desde dentro con una visión, con proyectos más amplios.

11. Faltan programas de intercambio de jóvenes de los clubes a México en proyectos donde puedan colaborar, aprender, y fortalecer sus raíces.

12. Falta una doble agenda, seguir apoyando a las comunidades en México, pero, integrar el empoderamiento en EU, participar en la agenda de reivindicaciones de todos los migrantes en EU por la Reforma Migratoria y otras demandas cívicas (cultura, idioma, ciudadanía, derechos laborales, derechos humanos, etc.)

13. Falta tener un inventario de nochistlenses exitosos para reconocerles su trayectoria e invitarlos a respaldar los proyectos de los clubes y sus comunidades de origen ("padrinos de las comunidades")

Respecto a los avances y fortalezas de los clubes nochistlenses se plantearon las siguientes:

1. La unidad que existe entre los nochistlenses, sus comunidades y los clubes.

2. La capacidad de convocatoria para realizar eventos culturales, religiosos, deportivos, etc. con miles de asistentes. Los animeños tienen 40 años festejando su día y funcionan desde los años sesenta con el 0x1. Realizar durante 10 años la visita de San Sebastián y la Virgen de Toyahua.

3. El amor a la tierra como fortaleza colectiva.

4. La participación intergeneracional en los clubes. 
5. La capacidad de aportar obras a las comunidades de origen que elevan su bienestar.

6. Que ya hay contrapartes en las comunidades de origen.

7. Mejor organización que permitió pasar de clubes a Asociación de Clubes Nochistlenses y a su registro como Non Profit Organization.

8. Las colaboraciones y alianzas con la USC, UCLA, UAZ, etc.

9. La estrategia de incubadora de clubes. Un club maduro da el aval a un nuevo club el primer año para que luego este en el segundo ya funcione plena y legalmente en el $2^{\circ}$, estrategia que explica el crecimiento de estos clubes en EU. Ojo, experiencia negativa de 4 clubes de Jerez que desaparecen y surge Clubes Unidos de Jerez que dan los avales para todos los proyectos.

10. Liderazgo de los clubes nochistlenses en la FCZSC y las organizaciones migrantes mexicanas.

11. Trabajo, unidad y transparencia las claves.

12. Promotores de nuevas políticas públicas.

13. Gran potencial de los clubes para colaborar en el desarrollo económico y social del municipio y sus comunidades. La Asociación de Clubes Nochistlenses y la FCZSC tiene gran potencial para asumir retos y proyectos más amplios en la lucha por el empoderamiento en EU; construcción de un Centro Cultural Zacatecano con aulas, salones de conferencias, salones de reuniones y bailes, canchas deportivas y colaborar en proyectos de desarrollo local y regional en Zacatecas.

Sobre los retos a 5,10 y 20 años se hicieron las siguientes propuestas:

1. Buscar elementos que mantengan e incrementen la unidad en los años siguientes.

2. Motivar la mayor participación de jóvenes. Buscar una agenda a partir de sus propios intereses (educación, cultura, esparcimiento, etc.)

3. Buscar opciones de intercambios culturales y educativos entre California y Zacatecas.

4. Valorar la propuesta de Mexican Corps de la Dra. Sandy Nichols de la Universidad de Berkeley como una opción de aprovechar a los universitarios de origen zacatecano en proyectos de desarrollo local con enfoque transnacional.

5. Preparar la realización de la Planeación Estratégica en los meses siguientes que lleve al Plan de Acción, a los instrumentos, a los responsables de cada acción y mecanismos de allegarse los recursos técnicos y financieros.

6. Vincular las becas a proyectos de clubes y comunidades de origen como mecanismo de corresponsabilidad de los beneficiarios para formar nuevos líderes en México y USA.

7. Promover que la FCZSC haga su Planeación Estratégica para buscar complementariedad, promover eventos más proactivos, mayor organización y capacitación de los clubes, promocionar más los talleres de ciudadanía; talleres sobre acceso a las universidades en Estados Unidos, talleres para lograr la residencia, etc.

8. Establecer programas de formación de nuevos liderazgos comunitarios.

9. Luchar por más visas para estudiantes zacatecanos.

10. Crear la Red de Talentos Zacatecanos.

11. Crear la Red de Empresarios Zacatecanos en California.

12. Promover la derogación de trabas en la Secretaría de Hacienda en México que impide la importación de tecnología a empresarios e investigadores de origen zacatecano.

13. Trabajar por nuevos programas de apoyo a los migrantes empresarios en México. Aprovechar las lecciones del Small Business de E.U.

14. Aprovechar la demanda interna, el mercado que representa la población zacatecana en California y EU para la exportación de productos zacatecanos, para proyectos de 
economía solidaria de los clubes y la FCZSC como panaderías, alimentos, bebidas, seguros, microfinanciamiento, automotrices y la construcción del Centro Cultural Zacatecano.

15. Ver la posibilidad de replicar el modelo de escuela de "Semillas del Pueblo" en California, en la cual se imparte una educación sólida y se fortalecen las raíces culturales latinas y el dominio de varios idiomas.

16. Reformular el reglamento de becas para México y los Estados Unidos de la Asociación de Clubes Nochistlenses y la FCZSC.

Por lo antes expuesto queda claro como las organizaciones de migrantes mexicanas están promoviendo un cambio social y cívico hacia el control social y rendimiento de cuentas en las políticas públicas y los programas gubernamentales en los que ellos participan y están buscando incrementar su organización y capacitación en Estados Unidos para avanzar en su empoderamiento en aquel país y potenciar su apoyo a los proyectos de desarrollo local en las comunidades de origen. Esta demanda ciudadana hacia los tres niveles de gobierno, que genera irritación frecuentemente entre funcionarios diversos, tal como ha sucedido con otras demandas migrantes, tarde que temprano terminará produciendo las reformas institucionales necesarias para su satisfacción como ya ha sucedido en otras etapas de la vida del Programa $3 \times 1$. Pero, además, al comenzar a visualizar sus comunidades y clubes en una visión de desarrollo local con enfoque transnacional, en el cual el Programa "Tres por Uno" es un instrumento muy importante de organización comunitaria transnacional permite que ellos reivindiquen el derecho que de todos los mexicanos al desarrollo económico y social, incluidos los 12 millones que en ausencia de este tuvieron que verse forzados a emigrar a los Estados Unidos. Así, cada vez más los migrantes plantean la exigencia al Estado mexicano de un nuevo tipo de políticas de Estado sobre Desarrollo y Migración que incidan sobre las causas estructurales que han expulsado al $10 \%$ de la población nacional y permitan que a mediano plazo la emigración sea una opción más de los ciudadanos y no una necesidad como sucede hasta ahora (García Zamora, 2009).

\section{LOS IMPACTOS CULTURALES}

Los datos estadísticos del Consejo Nacional de Población de 2005 muestran como el 96\% de los municipios de México cuenta con migrantes internacionales, evidenciando la creciente transnacionalización del país, que también se expresa por los enormes montos de remesas familiares que en 2008 ascendieron a 25 mil millones de dólares que beneficiaron a más de 1.6 millones de hogares. Estos dos indicadores estructurales junto con larga filantropía de las organizaciones migrantes por varias décadas en sus estados y comunidades de origen ha transformado la visión que desde México se tiene de esos clubes, que en el pasado se veían como los "apátridas" que habían abandonado el país. Ahora, crecientemente se les reconoce como un nuevo actor social que incide en el desarrollo de las comunidades, municipios y regiones donde la migración internacional es masiva y de larga duración como en Zacatecas y Michoacán. Ello explica que sea en esos estados donde se modificaron sus Constituciones para permitir que los migrantes puedan ser electos alcaldes y diputados locales y donde la organización migrante trasnacional tiene un impacto social, político y cultural en amplias de regiones de ellos. En el caso de Zacatecas, al interior del estado no existe una fuerza social organizada equivalente, con los impactos económicos, sociales y políticos que tienen las organizaciones migrantes, con capacidad de negociación con los tres niveles para los programas gubernamentales que se relacionan con sus comunidades de origen. En el imaginario nacional los migrantes hoy en día, en general, son vistos como los mexicanos que 
habiendo sido expulsados del país, ahora, desde el exterior están contribuyendo a su mantenimiento, a su transformación y la construcción de un nuevo México transnacional que los migrantes luchan por que tenga democracia, equidad, empleo y bienestar para todos. Desde la perspectiva migrante, como decía el carismático y polémico Andrés Bermúdez: "el cambio vendrá del Norte". Falta un amplio movimiento social, una revolución ciudadana pacifica, que cambien las estructuras políticas actuales y que permita el diseño de las nuevas políticas públicas que posibilite que se haga realidad ese sueño de la mayoría de los 107 millones de habitantes que radicamos en México y los 30 millones de origen mexicano que radican en EU.

\section{CONCLUSIONES}

1. La larga duración de la emigración internacional mexicana es la clave fundamental que permite explicar la existencia de más de 900 clubes migrantes como soporte de la filantropía transnacional, que creada desde abajo y desde adentro, en los últimos ocho años ha devenido una incipiente política pública transnacional donde el carácter espontáneo es acotado por la normatividad definida por los altos niveles de gobierno.

2. El Estado mexicano al crear el Programa "Tres por Uno para Migrantes", institucionaliza la filantropía transnacional (parte de ella, porque los Clubes y otras asociaciones menos formalizadas promueven miles de acciones solidarias hacia sus comunidades de origen al margen del Programa oficial) la acota y dirige a través de la formulación de las reglas de operación, atentando contra su carácter espontáneo y generando un riego de corporativización estatal de Programa. La apertura del Estado mexicano hacia la formulación conjunta con las comunidades y clubes de las reglas de operación y el establecimiento de mecanismos consensuados de control social y rendimiento de cuentas puede llevar a una trasnacionalismo intermedio, resultado del debate y consenso continuo. De lo contrario, emergerá un trasnacionalismo desde arriba, la versión corporativista del Programa que seguramente provocará el abandono de la mayoría de las organizaciones migrantes quienes retomarán su filantropía espontánea, desde abajo y desde adentro de la comunidad migrante en forma independiente.

3. Los impactos económicos y sociales del Programa "Tres por Uno" son evidentes en más de 12 mil comunidades del país. Su aporte es contundente, en igualdad de condiciones económicas y sociales, de intensidad migratoria, etc. la existencia de clubes define un mayor nivel de organización y bienestar de la población por el financiamiento de proyectos $3 \times 1$.

4. Un aporte adicional, quizá más importante, se refiere a los impactos cívicos, sociales y políticos en términos de promover la organización ciudadana transnacional, en origen y destino: impulsar la participación ciudadana en la solución de los problemas de las comunidades y exigir la responsabilidad de los tres niveles de gobierno ante esa problemática.

5. Las organizaciones migrantes han sido pioneras en la exigencia de trasparencia, control social y rendimiento de cuentas sobre los recursos públicos del Programa "Tres por Uno" y demás programas sociales vinculados con sus comunidades.

6. Las Federaciones de Clubes Migrantes Mexicanas con mayor antigüedad, con mayor experiencia en la filantropía transnacional y en la negociación con el Estado mexicano, están desarrollando una etapa de maduración institucional en la cual ahora ven a sus comunidades y regiones de origen en una nueva visión de desarrollo con enfoque transnacional. El Programa "Tres por Uno" es un instrumento importante, pero, sólo una parte de una estrategia integral, 
con la que el Estado mexicano deberá establecer Políticas de Estado sobre Desarrollo y Migración si quiere erradicar las causas estructurales de la masiva migración internacional.

7. Bajo la nueva visión del desarrollo regional y local con enfoque transnacional, las organizaciones de migrantes y comunidades asumen que para poder actuar como verdaderos agentes activos de ese desarrollo deberán promover un proceso de organización y capacitación permanente, de fortalecimiento institucional, que les permita incidir en la formulación de las políticas públicas, en su aplicación, en su seguimiento y sus modificaciones.

8. En el contexto nacional de creciente oligarquización económica, social y política, en el cual se constata que un reducido número de empresas internacionales y nacionales cercanas al gobierno, tienen todo tipo de privilegios y protecciones que les aseguran beneficios de los más altos del mundo, la lucha de las organizaciones migrantes por otro desarrollo seguramente les llevará a realizar nuevas alianzas con organizaciones campesinas, con sindicatos, universidades y otras organizaciones sociales, capaces de modificar el rumbo político del país, signado hasta ahora por la extranjerización y la inequidad.

9. Zacatecas y Michoacán, entre otros estados, pueden ser el inicio de esa estrategia de desarrollo transnacional con políticas de Estado sobre Desarrollo y Migración. Pero, para que ello suceda se requiere de una mayor participación ciudadana, el fortalecimiento comunitario transnacional y voluntad política de las diferentes estructuras partidarias que actúan de la misma forma antidemocrática, excluyente y patrimonialista que el gobierno federal, reproduciendo el mismo modelo económico que caracteriza al país en los últimos 28 años por su vulnerabilidad, por el empobrecimiento de la población y la subordinación del país a la oligarquía internacional y nacional. Las nuevas iniciativas de desarrollo regional con enfoque transnacional que están impulsando desde abajo los migrantes podrán avanzar rápidamente con el establecimiento de verdaderas políticas públicas de Desarrollo y Migración y no simples programas gubernamentales reactivos, parciales y tardíos como sucede hasta ahora.

10. Las emergentes estrategias migrantes de desarrollo regional con enfoque transnacional están condicionadas por la grave situación económica, social, política y de violencia que vive el país. En efecto, México experimenta en 2010 tres grandes desafíos. La reorientación del modelo económico ante la debacle de la economía nacional en el 2009 del $8 \%$ del PIB y los impactos y lecciones de la crisis económica mundial, que reafirman las recomendaciones de Keynes, al ser el Estado quién evitó el colapso de la economía norteamericana, de Grecia y la Unión Europea; la guerra perdida del gobierno mexicano con la industria del crimen con más de 34 mil asesinatos en 3 años y un enorme costo de inseguridad e inestabilidad para toda la población del país, y la contienda presidencial del 2012, de la cual difícilmente habrá una reorientación económica o social. Sólo existen las opciones del populismo de derecha o populismo neosalinista, (ante la autodestrucción del único partido de izquierda) con el riesgo de que la sincronía de mayor pobreza, marginación, violencia, corrupción y el país entregado a los intereses extranjeros lleven a la ingobernabilidad total y propicien la intervención de Estados Unidos como lo sugirió recientemente en México un ex presidente de ese país.

\section{BIBLIOGRAFÍA}

ASOCIACIÓN DE CLUBES NOCHISTLENSES, Taller de Organización Comunitaria Transnacional. Federación de Clubes Zacatecanos del Sur de California, UCLA, Long Beach University, UAZ. Los Ángeles, 22 de abril, 2010. 
BURGESS, K. (2010), Retos y oportunidades en la cogestión de proyectos comunitarios transnacionales. Universidad de Tufts, FCZSC, FEDECMI, CONFEMEX, FEDECAMIN, Federación de Clubes Yucatecos-USA, Ciudad de Mèxico, 15-16 abril.

Diario Oficial de la Federación, 29 de enero, 2009.

Diario Oficial de la Federación, 28 de diciembre, 2009.

FERNÁNDEZ DE CASTRO, R.; GARCÍA ZAMORA R. y VILA A. (2006), El Programa 3xl para Migrantes. ¿Primera Política Transnacional en México? ITAM-UAZ-Miguel Ángel Porrúa.

GARCÍA ZAMORA, R. (2003), Migración, Remesas y Desarrollo Local, UZ.

GARCÍA ZAMORA, R. (2005), Migración, Remesas y Desarrollo: Los retos de las organizaciones migrantes en Estados Unidos. UAZ.

GARCÍA ZAMORA, R. (2009), Desarrollo Económico y Migración Internacional: Los desafíos de las políticas públicas en México, UAZ.

JIMÉNEZ, E. (2010), IFAI, Ciudad de México, 15 de abril.

OROZCO, M. (2004), "Hometown Associations and Their Present and Future Partnership: New Development Opportunities", Diálogo Interamericano.

PALAFOX, G. (2010), Retos y oportunidades en la cogestión de proyectos comunitarios transnacionales, Universidad de Tufts, FCZSC, FEDECMI, CONFEMEX, FEDECAMIN, Federación de Clubes Yucatecos. USA. Ciudad de México, 16 abril.

\section{Breve currículo:}

\section{Rodolfo García Zamora}

Docente Investigador de la Unidad Académica de Estudios del Desarrollo de la UAZ. Especialista en migración, remesas y desarrollo regional y desarrollo rural. Sus cargos incluyen los de evaluador del Consejo Nacional de Ciencia y Tecnología (CONACYT); evaluador de Ciencias Sociales de la Universidad Autónoma Metropolitana (UAM), campus Iztapalapa y del Colegio de la Frontera Norte (COLEF), así como evaluador y asesor del Doctorado Interinstitucional en Administración (DIA). Ha sido profesor del COLEF y de las Universidades Central y Autónoma de Barcelona (España). También es miembro del Sistema Nacional de Investigadores (nivel II). Es autor y coautor de más de diez libros y numerosos artículos en revistas especializadas. Es miembro de la RIMD y muchas otras redes de reconocidos académicos. También es integrante del Patronato de la organización Sin Fronteras I.A.P. (México) y miembro de la Asociación Mexicana de Estudios Rurales.

\section{Juan Manuel Padilla}

Docente Investigador de la Unidad Académica de Economía de la UAZ, especialista en Demografía y Migración, Doctor en Ciencias Sociales por la Universidad Autónoma de Aguascalientes, es autor de 2 libros Cambio Demográfico y Desigualdad Social en Zacatecas 1970-2005, y La Población de Zacatecas, ha publicado varios capítulos de libro con editoriales de calidad y es autor y coautor de varios artículos en revistas indexadas, ha fungido como director de la Licenciatura en Economía de la UAZ y ha desarrollado numerosos proyectos de investigación con financiamiento externo como colaborador y responsable. Miembro de la Red de Investigadores en Ciencias Sociales de Aguascalientes, Coahuila, Guanajuato, Michoacán, Querétaro, San Luis Potosí y Zacatecas. 